\title{
Familial Amyloid Neuropathy
}

National Cancer Institute

\section{Source}

National Cancer Institute. Familial Amyloid Neuropathy. NCI Thesaurus. Code C84554.

A rare inherited neuropathy characterized by deposition of amyloid in the peripheral nerves. 